\title{
Whose conflict is it anyway? Mobilizing research to save lives
}

\author{
MARTIN Fisher
}

The administration is faced with a constant conflict between the cultivator and the marauding elephant; this is a grave problem as the cultivator invariably uses his gun, generally inflicting wounds and making the animal a rogue. Several cases have been reported recently in which inhabitants have been attacked and killed by elephants. These animals have had to be officially proclaimed "rogues" and destroyed.

As Norris (1956) here makes clear, referring to problems around Gal Oya National Park, established in Sri Lanka (then Ceylon) in 1954, our relationship with nature is often far from peaceful, with harm and fatalities on both sides. Not unexpectedly, this journal is replete with narratives of apparent conflict between people and notable animal adversaries: in particular, mammalian carnivores (Inskip \& Zimmermann, 2009), the African Loxodonta africana (Hoare, 2000) and Asian elephant Elephas maximus (Smith \& Mishra, 1992), and the crocodile Crocodylus niloticus and hippopotamus Hippopotamus amphibius (Dunham et al., 2010).

These narratives in Oryx date from Volume 1 of 1950 (Gee, 1950) but are notably more common from 2000 onwards. The interactions described are of three, not necessarily mutually exclusive, types: (1) wild animals eating and/or damaging crops, (2) wild animals predating domestic livestock, and (3) wild animals injuring people, sometimes fatally-and vice versa. With respect to the first, reports of raiding and/or damaging crops mostly involve elephants. Farmers and conservationists have exhibited great ingenuity in devising or suggesting methods to discourage or prevent them entering crop fields, including electric fences (Hislop, 1956), capture and relocation of raiding individuals (Wienman, 1958), controlled shooting (Thouless, 1994), a combination of early warning and communal guarding (Sitati \& Walpole, 2006), thunderflashes (Sitati \& Walpole, 2006), the application to rope barriers of grease extracted from chilli Capsicum sp. (Parker \& Osborn, 2006; Sitati \& Walpole, 2006; Hedges \& Gunaryadi, 2010), masking the smell of ripening rice (Santiapillai \& Read, 2010) and playback of felid growls (Thuppil \& Coss, 2016).

Interactions of the second type arise mostly from the unsporting habit that carnivores have of feeding on easily taken domestic livestock (Hoogesteijn \& Hoogesteijn, 2008; Gusset et al., 2009). Methods used or recommended to prevent this include enclosures for protection of livestock and improved herding practices (Amador-Alcalá et al., 2013; Tumenta et al., 2013), the use of guarding dogs (Rigg et al., 2011), and in the case of cattle, keeping buffalo, which are more aggressive, in the same paddock (Hoogesteijn \& Hoogesteijn, 2008).

Martin Fisher Fauna \& Flora International, Cambridge, UK

E-mail martin.fisher@fauna-flora.org
The third type of interaction, involving harm to people and/or wild animals, is sometimes a result of wild animals predating livestock, as in retaliation for predation, but also occurs when people are otherwise occupied, such as collecting forest resources (Khan, 2009) or working on croplands (Silwal et al., 2016). Living in proximity to certain wild species is clearly dangerous and the number of human fatalities unpalatable (Nyhus \& Tilson, 2004; Dunham et al., 2010; Silwal et al., 2016), yet ways of reducing the likelihood of wild animals directly attacking people-such as translocation of problem individuals (Goodrich \& Miquelle, 2005; Boast et al., 2015) and use of dogs to warn of the presence of tigers Panthera tigris (Khan, 2009)-have been less reported.

Phrases such as human-wildlife, human-elephant and human-carnivore conflict, and similar, are widely used in describing these interactions between people and nature. However, although a convenient shorthand, these phrases may be misleading. They simultaneously embrace interactions that are direct and indirect, intended and unintended, and implicitly suggest both sides are consciously intent on interfering in the life of the other and that the various conflicts are amenable to a single, universal resolution. Some of these conflicts may be expressed better as the interaction of wildlife with livestock, as in vultures vs livestock - an emerging conflict in Spain in which griffon vultures Gyps fulvus are being blamed for the death of livestock irrespective of whether or not they are responsible (Margalida et al., 2014).

These matters aside, the increasing attention afforded to the troubled relationships between people and several wild species is now leading to novel ways of framing the problems and new techniques for reducing harm and fatalities, with an increased emphasis on the search for improved coexistence. Fresh approaches are clearly necessary: the interaction of cultivators and elephants described by Norris (1956) is not a quaint historical anecdote. More than 50 years later people and elephants in Sri Lanka had still not learnt to live together harmoniously, with $>100$ elephants and c. 50 people killed annually (Santiapillai \& Read, 2010).

Alternative ways of conceptualizing the interactions between people and wildlife (Mosimane et al., 2014; Vitali, 2014; Redpath et al., 2015) now offer new perspectives. Redpath et al. (2015) argued that many of the so-called conflicts between people and wildlife are actually conflicts '... between conservation and other human activities, particularly those associated with livelihoods', and that therefore '....we should distinguish between human-wildlife impacts and humanhuman conflicts and be explicit about the different interests involved in conflict'. It follows that acknowledging the role of 
conservation in such conflicts (Redpath et al., 2015) could offer new approaches for easing coexistence.

Irrespective of whose conflict it is, crop raiding by wild animals and depredation of livestock and people, and subsequent retaliation, continue. Promising new techniques for minimizing these impacts of people on wildlife-and vice versa-include improved communications to help reduce crop raiding (Graham et al., 2012), a photographic database of tigers that facilitates identification and relocation of problem animals (Karanth et al., 2014), examination of the costs and benefits of lethal vs non-lethal control of problem predators (McManus et al., 2015), collection of information on the factors associated with attacks on people by crocodiles (Pooley, 2015) and tigers (Silwal et al., 2016), and novel methodologies that help people agree on how to reduce losses of livestock to wildlife (Rust, 2016).

As space for cultivation, nature protection and harvesting of natural resources becomes more contested, there is added urgency to the search for new conceptual approaches and for novel methods that are specific to individual species, places and situations. To paraphrase Pooley (2015), the ever greater ingenuity of thought and research now needs to be mobilized to save lives, of people and of wild species.

To mark Volume 50 of Oryx this Editorial and the references cited herein are freely available as a virtual issue of the journal at http://journals.cambridge.org.

\section{Acknowledgements}

I thank Bill Adams and Cella Carr for their invaluable critiques.

\section{References}

Amador-Alcalá, S., Naranjo, E.J. \& Jiménez-Ferrer, G. (2013) Wildlife predation on livestock and poultry: implications for predator conservation in the rainforest of south-east Mexico. Oryx, 47, 243-250.

BoAst, L.K., Good, K. \& KLeIN, R. (2015) Translocation of problem predators: is it an effective way to mitigate conflict between farmers and cheetahs Acinonyx jubatus in Botswana? Oryx, dx.doi.org/10. 1017/So030605315000241.

Dunham, K.M., Ghiurghi, A., Cumbi, R. \& Urbano, F. (2010) Human-wildlife conflict in Mozambique: a national perspective, with emphasis on wildlife attacks on humans. Oryx, 44, 185-193.

Gee, E.P. (1950) Wild elephants in Assam. Oryx, 1, 16-22.

Goodrich, J.M. \& Miquelle, D.G. (2005) Translocation of problem Amur tigers Panthera tigris altaica to alleviate tiger-human conflicts. Oryx, 39, 454-457.

Graham, M.D., Adams, W.M. \& Kahiro, G.N. (2012) Mobile phone communication in effective human-elephant conflict management in Laikipia County, Kenya. Oryx, 46, 137-144.

Gusset, M., Swarner, M.J., Mponwane, L., Keletile, K. \& McNutt, J.W. (2009) Human-wildlife conflict in northern Botswana: livestock predation by Endangered African wild dog Lycaon pictus and other carnivores. Oryx, 43, 67-72.

Hedges, S. \& Gunaryadi, D. (2010) Reducing human-elephant conflict: do chillies help deter elephants from entering crop fields? Oryx, 44, 139-146.

Hislop, J.A. (1956) Elephants and electric fences. Oryx, 3, 255-258.
Hoare, R. (2000) African elephants and humans in conflict: the outlook for co-existence. Oryx, 34, 34-38.

Hoogesteijn, R. \& Hoogesteijn, A. (2008) Conflicts between cattle ranching and large predators in Venezuela: could use of water buffalo facilitate felid conservation? Oryx, 42, 132-138.

Inskip, C. \& ZimmermanN, A. (2009) Human-felid conflict: a review of patterns and priorities worldwide. Oryx, 43, 18-34.

Karanth, K.U., Kumar, N.S. \& Vasudev, D. (2014) Photographic database informs management of conflict tigers. Oryx, 48, 484-484. Khan, M.M.H. (2009) Can domestic dogs save humans from tigers Panthera tigris? Oryx, 43, 44-47.

Margalida, A., CAmpión, D. \& Donázar, J.A. (2014) Vultures vs livestock: conservation relationships in an emerging conflict between humans and wildlife. Oryx, 48, 172-176.

McManus, J.S., Dickman, A.J., Gaynor, D., Smuts, B.H. \& Macdonald, D.W. (2015) Dead or alive? Comparing costs and benefits of lethal and non-lethal human-wildlife conflict mitigation on livestock farms. Oryx, 49, 687-695.

Mosimane, A.W., McCool, S., Brown, P. \& Ingrebretson, J. (2014) Using mental models in the analysis of human-wildlife conflict from the perspective of a social-ecological system in Namibia. Oryx, 48, 64-70.

Norris, C.E. (1956) A new wild life reserve in Ceylon. Oryx, 3, 240-243. Nyhus, P.J. \& Tilson, R. (2004) Characterizing human-tiger conflict in Sumatra, Indonesia: implications for conservation. Oryx, 38, 68-74.

PArker, G.E. \& Osborn, F.V. (2006) Investigating the potential for chilli Capsicum spp. to reduce human-wildlife conflict in Zimbabwe. Oryx, 40, 343-346.

Pooley, S. (2015) Using predator attack data to save lives, human and crocodilian. Oryx, 49, 581-583.

Redpath, S.M., Bhatia, S. \& Young, J. (2015) Tilting at wildlife: reconsidering human-wildlife conflict. Oryx, 49, 222-225.

Rigg, R., Finďo, S., Wechselberger, M., Gorman, M.L., SilleroZubiri, C. \& Macdonald, D.W. (2011) Mitigating carnivorelivestock conflict in Europe: lessons from Slovakia. Oryx, 45, 272-28o.

Rust, N.A. (2016) Can stakeholders agree on how to reduce humancarnivore conflict on Namibian livestock farms? A novel Q-methodology and Delphi exercise. Oryx, dx.doi.org/10.1017/Soo30605315001179.

Santiapillai, C. \& Read, B. (2010) Would masking the smell of ripening paddy-fields help mitigate human-elephant conflict in Sri Lanka? Oryx, 44, 509-511.

Silwal, T., Kolejka, J., Bhatta, B.P., Rayamajhi, S., Sharma, R.P. \& Poudel, B.S. (2016) When, where and whom: assessing wildlife attacks on people in Chitwan National Park, Nepal. Oryx, dx.doi. org/10.1017/Soo30605315001489.

Sitati, N.W. \& Walpole, M.J. (2006) Assessing farm-based measures for mitigating human-elephant conflict in Transmara District, Kenya. Oryx, 40, 279-286.

Smith, J.L.D. \& Mishra, H.R. (1992) Status and distribution of Asian elephants in central Nepal. Oryx, 26, 34-38.

Thouless, C.R. (1994) Conflict between humans and elephants on private land in northern Kenya. Oryx, 28, 119-127.

Thuppil, V. \& Coss, R.G. (2016) Playback of felid growls mitigates crop-raiding by elephants Elephas maximus in southern India. Oryx, 50, 329-335.

Tumenta, P.N., de Iongh, H.H., Funston, P.J. \& Udo de Haes, H. A. (2013) Livestock depredation and mitigation methods practised by resident and nomadic pastoralists around Waza National Park, Cameroon. Oryx, 47, 237-242.

Vitali, C. (2014) A frame-analytical perspective on conflict between people and an expanding wolf Canis lupus population in central Italy. Oryx, 48, 575-583.

Wienman, A.N. (1958) With elephants and pannikans in Ceylon. Oryx, 4, 317-321. 